\title{
Halothane anaesthesia does not modify the cardiovascular response to phenyl- ephrine in man
}

Conflicting results exist regarding the ability of halothane to alter the vascular response to alpha, adrenergic agonists in animals. Because data from humans are lacking, we studied the haemodynamic response to phenylephrine (PHE) in eight patients about to undergo coronary artery bypass surgery before and during halothane anaesthesia. After obtaining baseline measurements in patients while awake, the responses to PHE infusion at 30, 40, and $50 \mu \mathrm{g} \cdot \mathrm{min}^{-1}$ were determined. New baseline measurements were made following stabilisation during anaesthesia with halothane, one per cent inspired in oxygen, prior to surgical incision. Then the responses to identical PHE doses were measured again. Halothane did not influence the cardiovascular response to PHE: there was no dose-response shift for any cardiovascular variable. No arrhylhmias or signs of ischaemia were observed. We conclude that one per cent halothane anaesthesia does not attemate PHE-induced vasoconstriction in man.

Des études contradictoires existent concernant la capacité de I'halothane d'altérer la réponse vasculaire aux agonistes alpha, adrénergique chez l'animal. A cause d'un manque de donnée chez l'humain, on a étudié la réponse hémodynamique au phényléphrine (PHE) chez huit patients devamt subir un pontage aorto-coronarien avant et pendant à l'anesthésie à l' halothane. après l'obtention des mesures de base chez les patients

\author{
Key words \\ ANAESTHETICS, VOLATILE: halothane; \\ SYMPATHETIC NERVOUS SYSTEM: pharmacology, \\ phenylephrine; \\ SURGERY: cardiac.
}

From the Department of Cardiothoracic Anesthesiology, The Cleveland Clinic, 9500 Euclid Avenue, Cleveland, Ohio 44106.

Address correspondence to: Dr. D. F. Grum, Department of Anesthesiology, University of Tennessee, Memphis, 877 Jefferson Avenue, Chandler Building FG-023, Memphis, Tennessee 38103 . réveillés, les réponses à la perfusion de PHE à 30, 40 el 50 $\mu \mathrm{g} \cdot \mathrm{min}^{-1}$ ont été déterminées. De nouvelles mesures de base ont été faites après stabilisation pendant l'anesthésie avec l' halothane un pour cent inspiré avec l'oxygène avant l'incision chirurgicale. Puis les réponses aux doses équivalentes de PHE ont été mesurées de nouveau. L'halothane n'a pas infuencé la réponse cardio-vasculaire au PHE : il n'y avair aucune translocation de la courbe de dose-réponse pour aucune des variables hémodynamiques. Aucune arythmie el aucun signe d'ischémie n'a été observé. On conclut qu'un pour cent d'halothane lors de l'anesthésie n'atténue pas la vasoconstriction induite par le PHE chez l'homme.

Halothane has been demonstrated to attenuate alpha $a_{2}$ - but not alpha, ${ }_{1}$-adrenergic vasoconstriction in vivo and in vitro using a rat saphenous vein preparation. 'However, this finding is at variance with the halothane-mediated dosedependent reduction in phenylephrine-induced contraction of rat aortic strips described by others. ${ }^{2}$ Furthermore, the influence of halothane on vasoconstriction induced by phenylephrine (PHE) in man has not been described. Phenylephrine, a selective alpha ${ }_{1}$-adrenoceptor agonist, is commonly utilized to support systemic pressures during coronary artery bypass surgery (CABG). To evaluate the possibility that its haemodynamic effects might be attenuated by halothane, we examined the cardiovascular response to $\mathrm{PHE}$ of patients scheduled for CABG prior to and during halothane anaesthesia before the commencement of surgery.

\section{Methods}

After approval of the protocol by the institutional Human Research Projects Committee and Institutional Review Board, and after obtaining written informed consent from all subjects, eight male patients without systemic disease and with normal left ventricular function who were scheduled for elective coronary artery bypass graft surgery (CABG) were studied. The patients were not taking any medications other than occasional sublingual nitrates 
as needed for angina pectoris. Premedication consisted of morphine sulfate $\left(0.1 \mathrm{mg} \cdot \mathrm{kg}^{-1}, \mathrm{IM}\right)$, scopolamine $(0.4$ $\mathrm{mg}, \mathrm{IM})$, and transderm nitroglycerin $(5 \mathrm{mg})$ administered one hour before arrival in the operating room suite. No patient had taken sublingual nitrates within the previous $12 \mathrm{hr}$. Oxygen, $3 \mathrm{~L} \cdot \mathrm{min}^{-1}$ by nasal prongs, was administered to all patients upon arrival. The electrocardiogram (standard and augmented limb leads, and $V_{5}$ ), heart rate, and intra-arterial blood pressure at the radial artery were monitored, and a pulmonary artery catheter was inserted via the right internal jugular vein for determination of pulmonary artery pressures and cardiac index.

The following haemodynamic variables were measured and calculated in patients while awake before and after PHE infusions at 30,40 , and $50 \mu \mathrm{g} \cdot \mathrm{min}^{-1}$ : heart rate (HR), diastolic and systemic arterial blood pressures (DBP, MAP), diastolic and mean pulmonary artery pressures (PAD, PAM), pulmonary capillary wedge pressure (PCWP), central venous pressure (CVP), cardiac index $(\mathrm{CI})$, and systemic and pulmonary vascular resistances (SVR, PVR). The endpoint for each rate of infusion of PHE, after which haemodynamic measurements were made, was stabilisation of the response of the systemic arterial blood pressure (5-10 $\mathrm{min}$ ). Upon completing the measurements following each rate of infusion, the effects of PHE were allowed to subside and the haemodynamic variables returned to pre-PHE baseline in all patients. Anaesthesia was induced with thiopentone (2-3 mg. $\left.\mathrm{kg}^{-1}\right)$, utilizing a pancuronium-metocurine mixture $(0.4$ $\mathrm{mg} \cdot \mathrm{ml}^{-1}+1.6 \mathrm{mg} \cdot \mathrm{ml}^{-1}: 1 \mathrm{ml} \cdot 10 \mathrm{~kg}^{-1}$ ) for neuromuscular blockade during and following tracheal intubation. Lidocaine (100 mg) was used to attenuate the haemodynamic response to tracheal intubation. Anaesthesia was maintained with halothane, one per cent inspired, in oxygen. The ventilator was adjusted to maintain normal acid-base status and $\mathrm{PaCO}_{2}$ in each patient. After cardiovascular stability was achieved during halothane administration (approximately 20-30 min), new baseline haemodynamic measurements were obtained and the cardiovascular responses to PHE infusions at 30,40 and $50 \mu \mathrm{g} \cdot \mathrm{min}^{-1}$. Data were analyzed by paired $\mathrm{t}$ tests and by analysis of variance (ANOVA) for differences between the two study periods (before and during anaesthesia).

\section{Results}

The mean age of the patients was $57 \pm 8 \mathrm{yr}$ and their mean weight was $80 \pm 11 \mathrm{~kg}$. Blood pressures and heart rates upon arrival in the operating room suite did not differ from those recorded in the hospital rooms. No arrhythmias or signs and symptoms of ischaemia (ST-T segment changes, sudden large increase in PCWP, nor angina pectoris or other symptoms while awake) were observed in any
TABLE I Comparison of baseline haemodynamic data before (awake) and following anaesthesia (halothane)

\begin{tabular}{lcc}
\hline & Awake & Halothane \\
\hline HR (beats $\left.\cdot \mathrm{min}^{-1}\right)$ & $67 \pm 5$ & $73 \pm 3$ \\
MAP $(\mathrm{mmHg})$ & $94 \pm 6$ & $74 \pm 4^{*}$ \\
DBP $(\mathrm{mmHg})$ & $76 \pm 4$ & $64 \pm 3^{*}$ \\
SVR (dyne $\left.\cdot \mathrm{sec} \cdot \mathrm{cm}^{-5}\right)$ & $1440 \pm 177$ & $1400 \pm 176$ \\
PAM $(\mathrm{mmHg})$ & $18 \pm 2$ & $15 \pm 1$ \\
PAD $(\mathrm{mmHg})$ & $13 \pm 2$ & $11 \pm 1$ \\
PVR $\left(\mathrm{dyne} \cdot \mathrm{sec} \cdot \mathrm{cm}^{-5}\right)$ & $118 \pm 46$ & $110 \pm 23$ \\
PCWP $(\mathrm{mmHg})$ & $10 \pm 1$ & $10 \pm 1$ \\
CVP $(\mathrm{mmHg})$ & $7 \pm 1$ & $7 \pm 1$ \\
Cl $\left(\mathrm{L} \cdot \mathrm{min}^{-1} \cdot\right.$ meter $\left.^{-2}\right)$ & $2.8 \pm .3$ & $2.2 \pm .2^{*}$ \\
\hline
\end{tabular}

Values are mean $\pm \mathrm{SD}(n=8)$. HR = heart rate; MAP = mean systemic arterial pressure; DBP = systemic diastolic blood pressure; SVR $=$ systemic vascular resistance; $P A M=$ mean pulmonary artery pressure; $\mathrm{PAD}=$ pulmonary artery diastolic pressure; $\mathrm{PVR}=$ pulmonary vascular resistance; $\mathrm{PCWP}=$ pulmonary capillary wedge pressure;

$\mathrm{CVP}=$ central venous pressure; $\mathrm{CI}=$ cardiac index .

*Significant $(P<0.05)$ difference from awake value.

patient at any time during the study. Arterial blood gas analyses prior to and during halothane anaesthesia were normal.

The baseline haemodynamic measurements in patients both awake and anaesthetized are summarized in Table 1 . Following stabilisation under halothane anaesthesia, the new baseline MAP and DBP were significantly decreased from the unanaesthetized state. This was accompanied by a significant decrease in $\mathrm{CI}$, without any significant change being noted in PAM, PAD, CVP, PCWP, SVR, or PVR. The increase in HR was not statistically significant.

The cardiovascular responses to PHE prior to and after halothane anaesthesia are summarized in Table II. In awake patients, PHE caused significant increases in MAP, DBP (except at PHE: $30 \mu \mathrm{g} \cdot \mathrm{min}^{-1}$ ), SVR (except at PHE: $30 \mu \mathrm{g} \cdot \mathrm{min}^{-1}$ ), and PAD compared with baseline. These changes were accompanied by significant reductions in $\mathrm{HR}$ and $\mathrm{CI}$, with significant increases in PCWP and PVR (except at PHE: $30 \mu \mathrm{g} \cdot \mathrm{min}^{-1}$ ). The increases in DBP at PHE 40 and $50 \mu \mathrm{g} \cdot \mathrm{min}^{-1}$ and the reductions in $\mathrm{HR}$ with each increase in PHE dose were significant when compared with the preceding value, but the changes in $\mathrm{CI}$ were not.

During halothane anaesthesia, MAP, DBP, SVR, CVP, and PCWP increased significantly from baseline values following infusion of PHE, with correspondingly significant decreases in $\mathrm{Cl}$ and HR (Table II). PVR did not change significantly in anaesthetized patients in response to PHE.

ANOVA was used to compare the differences in haemodynamic variables from baseline measurements with values found at the various $\mathrm{PHE}$ infusion rates before 
TABLE II Haemodynamic response to phenylephrine before and after halothane anaesthesia

\begin{tabular}{|c|c|c|c|c|c|c|}
\hline & \multicolumn{3}{|c|}{ Before halothane PHE dose $\left(\mu g \cdot \min ^{-1}\right)$} & \multicolumn{3}{|c|}{ After halothane PHE dose $\left(\mu \mathrm{g} \cdot \mathrm{min}^{-1}\right)$} \\
\hline & 30 & 40 & 50 & 30 & 40 & 50 \\
\hline$\Delta H R$ & $-7 \pm 4$ & $-10 \pm 5 \dagger$ & $-13 \pm 6^{\dagger}$ & $-10 \pm 7$ & $-15 \pm 9 \dagger$ & $-18 \pm 10$ \\
\hline$\triangle \mathrm{DBP}$ & $2 \pm 4^{*}$ & $5 \pm 6 \dagger$ & $8 \pm 6 \dagger$ & $7 \pm 7$ & $12 \pm 5 \dagger \ddagger$ & $13 \pm 7$ \\
\hline$\triangle \mathrm{MAP}$ & $5 \pm 6$ & $10 \pm 8$ & $15 \pm 9$ & $10 \pm 11$ & $16 \pm 10 \ddagger$ & $19 \pm 13$ \\
\hline$\Delta$ SVR & $116 \pm 229^{*}$ & $255 \pm 311$ & $413 \pm 416$ & $444 \pm 163 \ddagger$ & $522 \pm 325$ & $526 \pm 326$ \\
\hline$\triangle \mathrm{PAD}$ & $2 \pm 2$ & $2 \pm 2$ & $3 \pm 3$ & $2 \pm 2$ & $3 \pm 4$ & $4 \pm 5$ \\
\hline$\triangle \mathrm{PAM}$ & $3 \pm 2$ & $4 \pm 4$ & $5 \pm 3$ & $1 \pm 2 \ddagger$ & $3 \pm 3$ & $5 \pm 5$ \\
\hline$\Delta$ PVR & $10 \pm 52^{*}$ & $43 \pm 51$ & $45 \pm 45$ & $-2 \pm 37^{*}$ & $10 \pm 46$ & $35 \pm 43^{*}$ \\
\hline$\triangle \mathrm{PCWP}$ & $2 \pm 1$ & $3 \pm 1$ & $3 \pm 2$ & $2 \pm 2$ & $4 \pm 2$ & $4 \pm 3$ \\
\hline$\Delta C V P$ & $2 \pm 2$ & $2 \pm 3$ & $3 \pm 5$ & $3 \pm 3$ & $3 \pm 3$ & $4 \pm 2$ \\
\hline$\Delta \mathrm{Cl}$ & $-0.2 \pm 0.3$ & $-0.3 \pm 0.4$ & $-0.4 \pm 0.4$ & $-0.4 \pm 0.3$ & $-0.5 \pm 0.4$ & $-0.5 \pm 0.5$ \\
\hline
\end{tabular}

Values are mean \pm SD changes $(\Delta)$ from baseline $(n=8)$. See Table I for abbreviations. All changes significanl $(P<0.05)$ when compared with baseline except *.

†Significant change $(P<0.05)$ compared with preceding value.

$¥$ Significant differences $(P<0.05)$ at comparable doses, before vs after halothane

No differences are significant at $P<0.01$ (refer to text for discussion).

and during halothane anaesthesia. None of the differences were statistically significant at this level: the overall cardiovascular response of patients to PHE infusion was not influenced by the presence of halothane anaesthesia.

\section{Discussion}

Phenylephrine is an alpha-agonist drug which preferentially stimulates the alpha ${ }_{1}$-adrenoceptor ${ }^{3}$ and is commonly utilized to support blood pressure at various times during CABG surgery. The important finding in our study was the demonstration that halothane anaesthesia did not alter the overall cardiovascular response to infusion of PHE at dosages commonly administered during CABG. Thus, a normal pressor response to PHE can be expected under these conditions. This has not been previously reported in humans.

To determine whether halothane influences the cardiovascular response to alpha-agonists in the clinical setting, we studied patients about to undergo $\mathrm{CABG}$ surgery with normal left ventricular function, who were otherwise free from chronic illness and who took no chronic, daily medications other than occasional nitrates for relief of angina pectoris. However, preoperative medication was administered because it was felt to be a necessary part of each patient's preparation for the stress of surgery and anaesthesia. ${ }^{4}$ Although the use of nitroglycerin (NTG) with premedication introduced a known vasodilator, plasma levels from transdermal patches at one and two hours are extremely low $\left(0.2-0.3 \mathrm{ng} \cdot \mathrm{ml}^{-1}\right) .^{5}$ Since plasma concentrations of $\mathrm{I}-2 \mathrm{ng} \cdot \mathrm{ml}^{-1}$ are required to produce venodilatation, ${ }^{6}$ it is unlikely that transdermal nitroglycerin had any effect on vascular responsiveness to PHE.
The decrease in MAP that we measured after stabilisation of anaesthesia with one per cent halothane was secondary to depression of cardiac output and a slight decrease in SVR, accompanied by a small but significant increase in HR. This is similar to the finding by Eger $e t$ $a l .^{7}$ In contrast to those results we found no change in CVP. Also, PCWP did not change in our patients after halothane anaesthesia. This differs from the results of Delaney et al., measured after 20-30 minutes of 1/2 MAC halothane anesthesia or at 3/4 MAC in patients with coronary artery disease who were similarly premedicated, except for transdermal NTG. ${ }^{8}$ They found significant increases in CVP and PCWP. Their methodology differed from ours: their patients were given a halothane anaesthetic induction and assisted ventilation by mask, whereas our patients underwent thiopentone induction, neuromus cular blockade, tracheal intubation and positive-pressure ventilation during halothane anaesthesia.

Halothane increases venous compliance ${ }^{9}$ and, in patients with high sympathetic tone, decreases systemic vascular resistance. ${ }^{10}$ Various central and peripheral actions play a role in halothane-mediated vascular smooth muscle relaxation, ' including the inhibition of vasoconstrictor actions of catecholamines, both in vivo ${ }^{11}$ and in vitro. ${ }^{12,13}$ In order to determine more specifically the cause of halothane's antivasoconstrictor action against catecholamines, various studies in animals have been done utilizing nonspecific as well as selective agonists of postjunctional alpha, and alpha ${ }_{2}$ adrenoceptors. ${ }^{1,2,14,15}$ Results have not been consistent, possibly secondary to differences in methodology, differences in species, nonspecific versus selective agonist effect, and the types of blood vessels studied. 
Since halothane decreases blood pressure, other investigators have attempted to compensate pharmacologically for this depression and to eliminate any indirect reflexinduced actions of alpha agonists. Larach et al, titrated arginine vasopressin (AVP) in their anaesthetized animal preparation to examine whether halothane-induced hypotension reduced vascular responsiveness in rats. ${ }^{\prime}$ Kenny et al. studied the haemodynamic response to pressors in anaesthetized dogs following ganglionic, cholinergic, and beta adrenergic blockade in doses appropriate to block reflex change in heart rate. ${ }^{14}$ Because we attempted to measure vascular responsiveness to PHE in a realistic clinical situation, we did not undertake any of the above measures. As expected, halothane did decrease baseline systemic blood pressures before PHE administration, and PHE caused a reflex slowing of HR in our patients. However, the cardiovascular response curves to PHE during halothane did not differ significantly from those obtained prior to anaesthesia. Unlike the study of Kenny et al. ${ }^{14}$ we were unable to demonstrate a significant shift to the right of the dose-response curve for any haemodynamic parameter.

Acid-base abnormalities can influence alpha ${ }_{1}$ adrenoceptor responses. ${ }^{16}$ Acid-base status was normal in all our subjects while unanaesthetized. During anaesthesia, ventilation was adjusted to maintain acid-base normality and to keep arterial $\mathrm{PCO}_{2}$ unchanged from control. No patient required pharmacological therapy for correction of a metabolic abnormality.

Phenylephrine infusion (mean $=78 \pm 22 \mu \mathrm{g} \cdot \mathrm{min}^{-1}$ ) has been demonstrated to reverse the improvement in ST-segment depression observed during nitroglycerin administration in patients with acute myocardial infarction ${ }^{18}$ and with heart failure. ${ }^{18}$ Our patients, all of whom had coronary artery disease with normal left ventricular function, without remote or acute infarction, were free from angina pectoris while awake during PHE infusion and did not demonstrate electrocardiographic evidence of ischaemia while awake. We also did not observe any evidence of ischaemia (evidenced by ST-segment, Twave, or acute changes in PCWP) with PHE infusion during halothane anaesthesia.

Phenylephrine has been shown to increase guinea pig SA nodal pacemaker firing, ${ }^{19}$ which may be the result of a direct action on beta adrenergic receptors ${ }^{20.21}$ and from secondary release of norepinephrine. ${ }^{20,22}$ In our patients a reflex bradycardia predominated. We observed statistically significant decreases in HR at each level of PHE infusion in both awake and anaesthetized patients. We did not observe arrhythmias at any time with increasing doses of PHE and resulting increases in blood pressure, neither before nor during halothane anaesthesia. Although concluding that both myocardial alpha,-adrenoceptors and elevation of blood pressure are involved in the arrhythmogenic action of PHE, other investigators have similarly noted in dogs the failure of PHE alone to induce arrhythmias during halothane anaesthesia. ${ }^{23}$

In conclusion, we found that halothane, one per cent inspired, in oxygen did not alter the overall haemodynamic response to phenylephrine in patients who were not taking chronic cardiovascular medications, even though alone it did lower systemic blood pressure and depress cardiac output. The response to PHE infusion, in doses commonly used during anaesthesia for $\mathrm{CABG}$, was an increase in systemic and pulmonary blood pressures and a reduction in cardiac output that paralleled and was not significantly different from the response found in unanaesthetized patients. In addition, PHE in the doses employed, did not cause myocardial ischaemia and was not arrhythmogenic when given during anaesthesia with halothane in oxygen in patients with coronary artery disease and normal left ventricular function.

\section{References}

I Larach DR, Schuler HG, Derr JA, Larach MG, Hensley $F A, Z$ Zekkis $R$. Halothane selectively attenuates alpha $\mathbf{a}_{2}$-adrenoceptor mediated vasoconstriction, in vivo and in vitro. Anesthesiology 1987; 66: 781-91.

2 Sprague $\mathrm{DH}$, Yang JC, Ngai SH. Effects of isoflurane and halothane on contractility and the cyclic $3^{\prime}, 5^{\prime}$ -

adenosine monophosphate system in the rat aorta. Anesthesiology 1974; 40: 162-7.

3 van Meel JCA, de Jonge A, Timmermans PBMWM, van Zwieten $P A$. Selectivity of some alpha adrenoceptor agonists for peripheral alpha ${ }_{1}$ and alpha $_{2}$ adrenoceptors in the normotensive rat. J Pharmacol Exp Ther 1981; 219: $760-7$.

4 Waller JL, Zaidan JR, Kaplan JA, Bauman DI. Hemodynamic responses to preoperative vascular cannulation in patients with coronary artery disease. Anesthesiology 1982; 56: 219-21.

5 Corwin $S$, Reiffel JA. Nitratc therapy for angina pectoris. Current concepts about mechanism of action and evaluation of currently available preparations. Arch Intem Med 1985; 145: 538-43.

6 Armstrong PW, Armstrong JA, Marks GS. Pharmacokinetic-hemodynamic studies of intravenous nitroglycerin in congestive heart failure. Circulation 1980; 62: 160-6.

7 Eger El II, Simith NT, Stoelting RK, Cullen DJ, Kadis LB, Whitcher $C E$. Cardiovascular effects of halothane in man. Anesthesiology 1970; 32: 396-409.

8 Delaney TJ, Kistner JR, Lake CL, Miller ED. Myocardial function during halothane and enflurane anesthesia in patients with coronary artery disease. Anesth Analg 1980; 59: $240-4$. 
9 Caffrey JA, EcksteinJW, Hamilion WK, AbboudFM. Forearm venous and arterial responses to halothane and cyclopropane. Anesthesiology 1965; 26: 786-90.

10 Reiz S, Balfours E, Gusfavsson B el al. Effects of halothane on coronary hemodynamics and myocardial metabolism in patients with ischaemic heart disease and heart failure. Acta Anaesthesiol Scand 1982; 26: 133-8.

11 Christoforo $M F$, Brody MJ. The effects of halothane and cyclopropane on skeletal muscle vessels and baroreceptor reflexes. Anesthesiology 1968; 29: 36-43.

12 Price $M L$, Price $H L$. Effects of general anesthetics on contractile responses of rabbit aortic strips. Anesthesiology 1962; 23: 16-20.

13 Clark SC, MacCannell KL. Vascular responses to anaesthetic agents. Can Anaesth Soc J 1975; 22: 20-33.

14 Kenny D, Pelc LR, Brooks HL, Kampine JP, Schmeling $W T$, Warltier $D C$. Alterations of alpha, and alpha adrenoceptor-mediated pressor responses by halothane and isoflurane anesthesia. Anesthesiology 1989; 71 : 22434.

15 Muldoon SM, Vanhoutte PM, Lorenz RR, Van Dyke $R A$. Anesthesiology 1975; 43; 4I-8.

$16 \mathrm{McGrath} J C$. The variety of vascular alphaadrenoceptors. Trends Pharmacol Sci 1983; 4: 14-8.

17 Come PC, Flaherry JT, Baird MC et al. Reversal by phenylephrine of the beneficial effects of intravenous nitroglycerin in patients with acute myocardial infarction. N Engl J Med 1975; 293: 1003-7.

18 Borer JS, Redwood DR, Levilt B et al. Reduction in myocardial ischemia with nitroglycerin or nitroglycerin plus phenylephrine administered during acute myocardial infarction. N Engl J Med 1975; 293: 1008-12.

19 Stowe DF, Dujic Z, Bosnjak Z, Kalbfleisch JH, Kampine $J P$. Volatile anesthetics attenuate sympathomimetic actions on the guinea pig SA node. Anesthesiology 1988; 68: 887-94.

20 Nigro D. Scivoletro $R$. Mechanism of action of phenylephrine on isolated guinea-pig atria rate. Gen Pharmacol 1983; 14: 349-54.

21 Wagner J, Endoh M, Reinhardt $D$. Stimulation by phenylephrine of adrenergic alpha- and beta-receptors in the isolated perfused rabbit heart. Naunyn Schmiedebergs Arch Pharmacol 1974; 282: 307-10.

22 Verma SC, McNeill JH. Biochemical and mechanical effects of phenylephrine on the heart. Eur J Pharmacol 1974; 36: 447-50.

23 Hayashi Y, Sumikawa K, Tashiro C, Yoshiya I. Synergistic interaction of alpha $a_{1}$-and beta-adrenoceptor agonists on induction arrhythmias during halothane anesthesia in dogs. Anesthesiology 1988; 68: 902-7. 